

\title{
Maternal styles in a precocial bird
}

Florent Pittet, Cécilia Houdelier, Emmanuel de Margerie, Océane Le Bot, Marie-Annick Richard-Yris, Sophie Lumineau

\section{To cite this version:}

Florent Pittet, Cécilia Houdelier, Emmanuel de Margerie, Océane Le Bot, Marie-Annick RichardYris, et al.. Maternal styles in a precocial bird. Animal Behaviour, 2014, 87, pp.31-37. 10.1016/j.anbehav.2013.10.025 . hal-01021541

\section{HAL Id: hal-01021541 https://hal.science/hal-01021541}

Submitted on 29 Nov 2017

HAL is a multi-disciplinary open access archive for the deposit and dissemination of scientific research documents, whether they are published or not. The documents may come from teaching and research institutions in France or abroad, or from public or private research centers.
L'archive ouverte pluridisciplinaire HAL, est destinée au dépôt et à la diffusion de documents scientifiques de niveau recherche, publiés ou non, émanant des établissements d'enseignement et de recherche français ou étrangers, des laboratoires publics ou privés. 


\section{Maternal styles in a precocial bird} (1)

Florent Pittet, Cécilia Houdelier, Emmanuel de Margerie, Océane Le Bot, Marie-Annick Richard-Yris' Sophie Lumineau

UMR CNRS 6552 'Ethologie Animale et Humaine', Université de Rennes I, France Correspondence: sophie.lumineau@univ-rennes1.fr; florent.pittet@gmail.com

Care provided by females of many mammal species varies naturally between individuals; these differences in turn influence the phenotypic development of their offspring. When individual maternal behavioural traits are consistent over a number of breeding periods, maternal styles can be defined. These styles have been studied in a large range of mammalian species. Nevertheless, mammals rarely offer the possibility to dissociate mothers' behavioural influence from their genetic influence or their physiological influence via lactation. Here, we provide, for the first time, evidence of the existence of a precocial bird species' maternal styles. By using an adoption procedure we evaluated how maternal style affected the behaviour of Japanese quail, Coturnix coturnix japonica, chicks, via exclusively nongenomic mechanisms. As well as evidence for the existence of maternal styles in this species, we also found correlations between females' temperaments, maternal styles and their fostered chicks' development. Our findings indicate that maternal styles are key features that help understand nongenomic transmission of behavioural characteristics whose vectors have remained poorly understood.

Key-words: Coturnix coturnix japonica, Japanese quail, maternal styles, nongenetic influences, temperament 


\section{INTRODUCTION}

The way in which individuals behave in challenging situations can have significant fitness consequences (Dingemanse, Both, Drent, \& Tinbergen, 2004; Réale, Reader, Sol, McDougall, \& Dingemanse, 2007; Smith \& Blumstein, 2008). In a wide range of species, individual differences in behavioural reactions when facing challenges can remain consistent over time and situations (Réale et al., 2007; Rodríguez-Prieto, Martín, \& Fernández-Juricic, 2011). These behavioural consistencies have been studied mainly in nonreproductive contexts, focusing on several dimensions of fearfulness, exploration and sociality and have been termed temperaments or personalities (see Réale et al., 2007 for a review). Nevertheless, many vertebrates can also present individual differences related to reproductive behaviours. Maternal (or mothering) styles can be defined as the individual differences in the dimensions of care expressed by a female towards her young that remain consistent over several periods of maternal care (Albers, Timmermans, \& Vossen, 1999; Dwyer \& Lawrence, 2000). Maternal styles thus constitute an individual signature of maternal care that must be evaluated over several maternal care periods to make sure that individual differences in care are not due to individual differences in offspring characteristics. These styles are defined by dimensions of care, identified by the relationships between the behaviours of the maternal repertoire. For instance, consistent individual differences in the maternal behaviour of many nonhuman primate species appear in two dimensions of care: protection and rejection. These dimensions of care are independent and both are defined by several correlated care items (see Fairbanks, 1996; Groothuis \& Maestripieri, 2013). So far, maternal styles have been described in humans (van Ijzendoorn et al., 2000), nonhuman primates (Fairbanks, 1996) and altricial (Champagne, Francis, Mar, \& Meaney, 2003) and precocial (Dwyer \& Lawrence, 2000; Spinka et al., 2000) nonprimate mammals. Identifying and understanding the relationships between individual differences within and outside the family context to understand their coadaptation remains a 
key challenge (Roulin, Dreiss, \& Kölliker, 2010). By investigating the biological causes and consequences of these individual differences in the maternal care of several mammalian species, researchers have reported a link between maternal style and temperament. Mothers' temperaments influence maternal styles (Fairbanks, 1996; Maestripieri, 1993; Plush, Hebart, Brien, \& Hynd, 2011) and, in turn, maternal styles are reported to have a strong impact on offspring temperament (Schino, Speranza, \& Troisi, 2001; Weaver et al., 2004). For instance, anxious baboon, Papio spp. (Altmann, 1980) and rhesus monkey, Macaca mulatta (Maestripieri, 1993) females show high levels of protection of their infants, whereas rejection rates of Japanese macaques, Macaca fuscata, are reported to affect their infants' sociality (Schino et al., 2001). So far, mothering styles and their relationship with temperament have been studied only in mammalian species.

Maternal styles, as defined above, have never been rigorously identified in a bird species. Nevertheless, consistency of a particular parental care behaviour has been described in altricial birds, suggesting the potential existence of parental styles. For example, food provisioning by a male house sparrow, Passer domesticus, can be consistent across broods and is not influenced by his partner's efforts (Schwagmeyer \& Mock, 2003). Moreover, parents' temperaments can affect such care behaviour, thus suggesting a potential relationship between temperament and parenting style in birds. For example, the food provisioning and nest defence of titmice (Paridae) are related to their exploratory and aggressive behaviours (Hollander, Van Overveld, Tokka, \& Matthysen, 2008; Mutzel, Dingemanse, Araya-Ajoy, \& Kempenaers, 2013). Finally, bird mothers can strongly modify the behavioural development of their offspring via nongenetic influences occurring during the early postnatal period. In particular, these maternal effects have been reported to be strong in precocial birds, in which mothers can transmit nongenetically some of their temperament traits to chicks, including fearfulness (Houdelier, et al., 2011; Richard-Yris, Michel, \& Bertin, 2005) and traits related to sociality (Formanek, Houdelier, 
Lumineau, Bertin, \& Richard-Yris, 2008). Precocial birds are currently becoming the models of choice to investigate such maternal effects because the absence of lactation and the opportunity to carry out adoption procedures enable researchers to disentangle behavioural from physiological (Catalani et al., 2000; Hinde \& Captanio, 2010), genetic (Schino et al., 2001) and prenatal (Stamps \& Groothuis, 2010) influences. Nevertheless, the mechanisms associated with these influences remain unknown. In these precocial bird species, as in most mammals, mothers are the only caregivers and express a rich maternal behavioural repertoire to provide warmth and protection to their offspring and to stimulate their feeding behaviour until they can look after themselves (Nelson, 1995). Nevertheless, the implication of individual differences in the maternal behaviour of precocial hens has never been investigated in relation to these maternal influences.

We investigated the existence of maternal styles in a precocial bird species, the Japanese quail, Coturnix coturnix japonica, and the link between maternal styles and both mothers' and their offspring's temperaments. Using a recently described procedure to evaluate maternal care in this species (Pittet, Coignard, Houdelier, Richard-Yris, \& Lumineau, 2013), we analysed the maternal behaviour of 20 adult female Japanese quail over three consecutive maternal periods and evaluated their temperament and the temperament of their offspring. We asked the following questions: (1) can maternal styles be defined in a bird species and if so, (2) can a female's temperament predict her maternal style and (3) can maternal styles predict offspring behavioural characteristics? 


\section{METHODS}

\section{Housing conditions}

The quail studied originated from an industrial farm (Les Cailles de Chanteloup, CorpsNuds, France). In our laboratory, they were kept at $20 \pm 1{ }^{\circ} \mathrm{C}$ on a $12: 12 \mathrm{~h}$ light:dark cycle (lighting $=5001 \mathrm{x})$. Food provided was a high-protein cereal diet in the form of a mix of pellet for chicks and granulates for adult females (VEGAM, Cesson-Sévigné, France).

Twenty adult females arrived at the laboratory when they were 5 weeks old and were placed singly in wire-mesh cages $(100 \times 70 \mathrm{~cm}$ and $62 \mathrm{~cm}$ high) with opaque walls 7 weeks before their first brood to habituate them to their experimental environment. The cages contained a feeder and a water source with food and water available ad libitum. Water was available for drinking only and not for bathing. The females were 12, 37, 44 and 51 weeks old, respectively, for the first, second, third and fourth breeding periods (denoted BP0, BP1, BP2 and BP3) and stayed under the same constant environmental conditions throughout the experiment.

Chicks were from the same broiler line. For each breeding period, 120 1-day-old chicks (total sample $=480$ chicks) arrived at the laboratory and were placed in groups of 30 in four plastic cages (98x35 cm and $42 \mathrm{~cm}$ high) with wood shavings covering the floor and equipped with a heater $\left(38 \pm 1{ }^{\circ} \mathrm{C}\right)$ and food and water provided ad libitum.

After each breeding period, chicks were either used for other experiments or kept in boxes (200x200 cm and $280 \mathrm{~cm}$ high) with wood shavings covering the floor, at $20 \pm 1^{\circ} \mathrm{C}$ and under a 12:12 h light:dark cycle, until they could be used for breeding. The 20 females were used for other behavioural experiments and then placed in an outdoor aviary $(500 \times 500 \mathrm{~cm}$ and $300 \mathrm{~cm}$ high) with tall grass and several shelter areas. 
In the evening of the arrival of chicks, for each breeding period, females were shut in their nestbox $(20 \times 20 \times 20 \mathrm{~cm})$ and the light was immediately switched off. One hour later $(2100$ hours) we placed four chicks underneath each female. Chicks' solicitations during the night induce the females to become maternal (Richard-Yris, Michel, \& Bertin, 2005) by the following morning when the boxes are opened (0800 hours) . Females that did not accept the chicks (i.e. absence of warming behaviour after the release of the brood, expression of rejection behaviours) were excluded from the experiment; three females were excluded from $\mathrm{BP} 0$, one from $\mathrm{BP} 1$, two from BP2 and six from BP3. Any chick in a female's brood that showed signs of hypothermia (closed eyes, trembling, motionless) on the first day of each breeding period was replaced by a new chick (so that all broods included four chicks for all the females). The new chicks were ringed and of the same age but were not tested later as they did not spend the whole breeding period with a mother: 18 chicks were replaced for BP0, 23 for BP1, 11 for BP2 and 21 for BP3. After the first day, chicks quickly learn to warm one another (Pittet, Coignard, Houdelier, Richard-Yris, \& Lumineau, 2012) and we noted no further signs of hypothermia. We could not monitor signs of hypothermia at night since our presence in the breeding room during the dark phase would have disturbed the birds. We nevertheless checked for the absence of distress calls 30 min after the beginning of the dark phase.

\section{Behavioural measurements}

\section{Observation of maternal behaviour}

Maternal behaviour was observed on posthatching days (PHD) 2, 3, 4, 5, 7 and 9 of each maternal care period. The observation procedure was similar to that used by Pittet et al. (2013).

Both instantaneous scan sampling and focal animal sampling were equally distributed between the morning and afternoon periods and were carried out from behind one-way mirrors. The 20 adult females were observed using the instantaneous scan sampling method (interval: 4 
min, 60 observations/female/day) for $4 \mathrm{~h}$ on each observation day. The experimenter noted whether or not the female was warming the chicks, whether or not her warming posture covered the chicks entirely and her distance to each chick using five distance classes: close (chick in contact with hen), near (at no more than one chick length from the hen), far (chicks between one chick length and half a cage from the hen), distant (chick between half a cage and a cage length from the hen) and opposite (at one cage length). From these data, several indexes were calculated: (1) mean distance index $=\left[N_{\text {opposite }}+0.75 \times N_{\text {distant }}+0.5 \times N_{\text {far }}+0.25 \times N_{\text {near }}\right] /$ total chicks observed while not being warmed; (2) proportion of time spent warming $=$ scans in which warming occurred/total scans; and (3) index of warming posture quality $=$ scans in which warming occurred in a covering posture/scans in which warming occurred.

These observations were associated with two $5 \mathrm{~min}$ focal animal sampling observations on each observation day for each cage. The experimenter noted aggressive behaviour that included attacks (the mother attacks a chick while making threat vocalizations), pecking (the mother pecks at a chick with her beak closed), trampling of chicks and breaks in warming including the initiator of these breaks (mother or chick). The proportion of warming breaks initiated by the mother was calculated as warming breaks initiated by mother/total warming breaks observed.

On PHD10, to evaluate maternal reactivity, chicks were separated from their mothers whose reactions were assessed by a 5 min focal observation recording their vocalizations and latencies to return to feeding and resting.

\section{Temperament assessment of females and foster chicks}

Mothers were tested before and chicks were tested after the first breeding period. We applied tests commonly used to assess shyness, neophobia and social motivation in Japanese quail. We evaluated shyness by the time (maximum: $3 \mathrm{~min}$ ) mothers and chicks took to emerge 
from a dark shelter box into a novel well-lit environment in the emergence test (Jones, Satterlee, \& Cadd, 1999), and neophobia by their reactions to a novel object in a familiar environment, measured during a 10 min focal animal sampling observation. A 5 min open-field test evaluated the way individuals responded to both an unknown open environment and their first social isolation, and their social motivation was evaluated by their aptitude to approach three unfamiliar conspecifics in the runway test (Formanek et al., 2008). For more details on the tests see the Appendix.

\section{Data analyses}

As most data were not normally distributed we applied nonparametric statistics. The overall effects of maternal experience and age of chicks on maternal traits were investigated by Friedman tests followed by Nemenyi post hoc tests with Bonferroni alpha corrections to compare pairs. This initial analysis was carried out to determine the periods when maternal variables were not strongly influenced by maternal experience or by the chicks' age. It showed (see Appendix Table A1) that maternal variables differed strongly between the first and later breeding periods and that maternal traits on PHD7 and PHD9 differed from those on previous days of the breeding period. BP0 was excluded from analysis because of this strong effect of experience already reported (Pittet et al., 2013) and, to obtain a mean of each variable for each breeding period for each female, we averaged data from PHD2 to PHD5.

A principal component analysis (PCA) including maternal care variables (see above) was used to determine dimensions of maternal care. We focused on mother-chick interactions in the home cage to identify maternal styles, as described in the literature. Thus, we did not consider the results of the separation tests as a care variable to include in the PCA, since this test presents an artificial situation with disturbance of the brood and was carried out at the end of the care period. Kendall concordance tests were used to describe the consistency of 
individual differences across breeding periods. Kendall's coefficient of concordance analysing agreement among behavioural trait data or scores obtained by a PCA analysis is a classic statistical method to investigate maternal styles when more than two periods of care are involved (Albers et al., 1999; Dwyer \& Lawrence, 2000). As an analysis of concordance requires at least three repetitions, data for the six females that did not accept chicks for one of the last three breeding periods were excluded from the analysis. Kendall correlation tests were computed to analyse the relationship between maternal styles and temperament data. Data analyses were computed using XLStat (www.xlstat.com) and R (The R Foundation for Statistical Computing, Vienna, Austria, www.r-project.org).

\section{Ethical note}

All experiments were approved by the departmental direction of veterinary services (Illeet-Vilaine, France, permit number 005283) and were performed in accordance with the European Communities Council Directive of 24 November 1986 (86/609/EEC). Our breeding procedure and tests were approved by the regional ethics committee (agreement number: R2011-SLU-02).

Twenty adult females and 480 chicks were used for the four breeding experiments. As some females failed to adopt chicks, 20 was the minimum sample size needed to obtain sufficiently robust statistical results. We used a brood size of four chicks as a compromise between the size of a natural brood (5 - 10 chicks, Taka-Tsukasa 1935), which would be too large to handle, and a smaller brood size that might not elicit maternal care in females.

Birds were transported by car and the journey lasted $20 \mathrm{~min}$. Adult females were transported in aluminium crates $(70 \times 30 \mathrm{~cm}$ and $22 \mathrm{~cm}$ high), each containing six individual boxes, and chicks in groups of 30 in plastic boxes (40x40 $\mathrm{cm}$ and $15 \mathrm{~cm}$ high) with wood shavings covering the floor. Temperature was $20^{\circ} \mathrm{C}$ for the female transport and $30{ }^{\circ} \mathrm{C}$ for the chicks. 
Our females were housed singly because, under natural conditions, they generally stay some distance from one another and remain in social isolation while they incubate and care for their chicks which they do alone (Guyomarc'h \& Saint-Jalme, 1986). Housing females singly is consequently the usual laboratory procedure for breeding experiments (Bertin \& Richard-Yris, 2005; Houdelier et al., 2011). We did not provide hiding places because we needed to be able to observe all the five quail in a cage continuously to estimate interindividual distances and maternal behaviour. Nevertheless, the cages were behind one-way mirrors, and we checked that the females showed no stereotypies, distress calls or flight attempts, and that they carried out normal comfort behaviours such as dust bathing, which was facilitated by plastic netting covering the cage floor.

We observed some cases of maternal aggression. Two females that were excluded from opened the nestboxes in these three breeding periods. We detected these attacks on hearing the females' threat vocalizations and their chicks' loud vocalizations and therefore removed the chicks immediately. Chicks that were attacked showed only a slight feather loss on their neck but no bleeding or inflammation except during BP0 when three chicks' heads bled slightly. Injured chicks as well as all the excluded chicks (chicks of nonmaternal females and chicks that had to be replaced) were all put under a heater in plastic cages ( $98 \times 35 \mathrm{~cm}$ and $42 \mathrm{~cm} \mathrm{high)} \mathrm{for}$ the rest of the experiment. Chicks that showed signs of hypothermia swiftly recovered (in less than $1 \mathrm{~h}$ ). Chicks that were injured during BP0 were treated with an antiseptic (Vetidine) and an aerosol bandage (Aluspray) before they were placed in the cages. Signs of the attacks were no longer visible 1 week later. Aggressive (i.e. pecking and aggression) and abusive (trampling) behaviours towards chicks by females in the later part of the breeding period did not cause any feather loss, bleeding or inflammation and consequently did not justify any intervention. 


\section{RESULTS}

242

Maternal traits were objectively summarized by two dimensions of a PCA. Given the loadings of variables on the two factors (Fig. 1), they were respectively labelled 'aggression' and 'rejection versus warming' (see Fig. 1 legend for explanations). Females' scores on the two dimensions were not correlated (Kendall correlation test: $P>0.05$ ), demonstrating that maternal behaviour was truly multidimensional. We found a significant concordance of both females' aggression (Kendall concordance test: $\omega=0.62, N=14, P=0.03$; Fig. 2 a) and rejection $(\omega=$ 0.72, $N=14, P=0.008$; Fig. 2 b) scores over the breeding periods, demonstrating that interindividual differences revealed by these two dimensions were strong and consistent across care periods. We also tested directly the consistency of interindividual differences for each of the seven maternal variables recorded and found a significant concordance across breeding periods for each maternal trait (Kendall concordance test: $P<0.05)$.

Females' reaction to separation from their chicks was related to their maternal style. The more rejection the mothers showed, the less they reacted to separation from their chicks, producing fewer distress calls $(\tau=-0.22, N=42, P=0.05)$ and resuming feeding more rapidly $(\tau=-0.26$, $N=42, P=0.03)$.

\section{Relationships between maternal styles and temperament}

\section{Maternal temperament}

Maternal styles were correlated with several maternal temperament traits. Aggression scores were correlated with reaction-to-novelty scores. The more aggressive the mothers were towards chicks, the more they reacted to and avoided a novel object (Kendall correlation $\tau=0.43, N=$ $19, P=0.012$; Fig. 3a) and the fewer fear postures they adopted $(\tau=-0.40, N=19, P=0.02$; 
Fig. 3b). In addition, the more socially motivated the females behaved the more they rejected their chicks: the time they spent in contact with a social stimulus in the runway test was positively correlated with their rejection scores $(\tau=0.34, N=19, P=0.04$; Fig. 3c).

\section{Chicks' temperament}

As we found many significant correlations between chicks' behavioural data and the females' maternal styles, we summarized chicks' behavioural responses to our tests using a PCA to avoid type I errors. Chicks' behavioural traits were summarized by three axes, representing $65.56 \%$ of the variability. The first two factors represented two dimensions of their sociality: there were positive loadings for the vocalizations of socially isolated chicks in the open-field and emergence tests $(23.6 \%$ of variability) and their motivation to move closer to unfamiliar conspecifics in the runway test (23.4\% of variability). The third axis ( $18.6 \%$ of variability) represented chicks' reactivity in a novel environment; there were positive loadings for the number of steps in an open field and negative loadings for latencies to emerge from a shelter into an unfamiliar cage. We found that maternal rejection scores were positively correlated with socially isolated chicks' vocalization scores $(\tau=0.23, N=57, P=0.013)$ and with their scores for proximity to unfamiliar conspecifics $(\tau=0.22, N=57, P=0.016)$, so that the more rejected the chicks were, the more socially motivated they were subsequently. We found no correlation between care scores and chicks' reactions to novelty scores $(P>0.05)$. 


\section{Factor 1:}

Aggression $\rightarrow$

281

282

283

284

285
Factor 2:

Rejection $\rightarrow$

$\leftarrow$ Warming

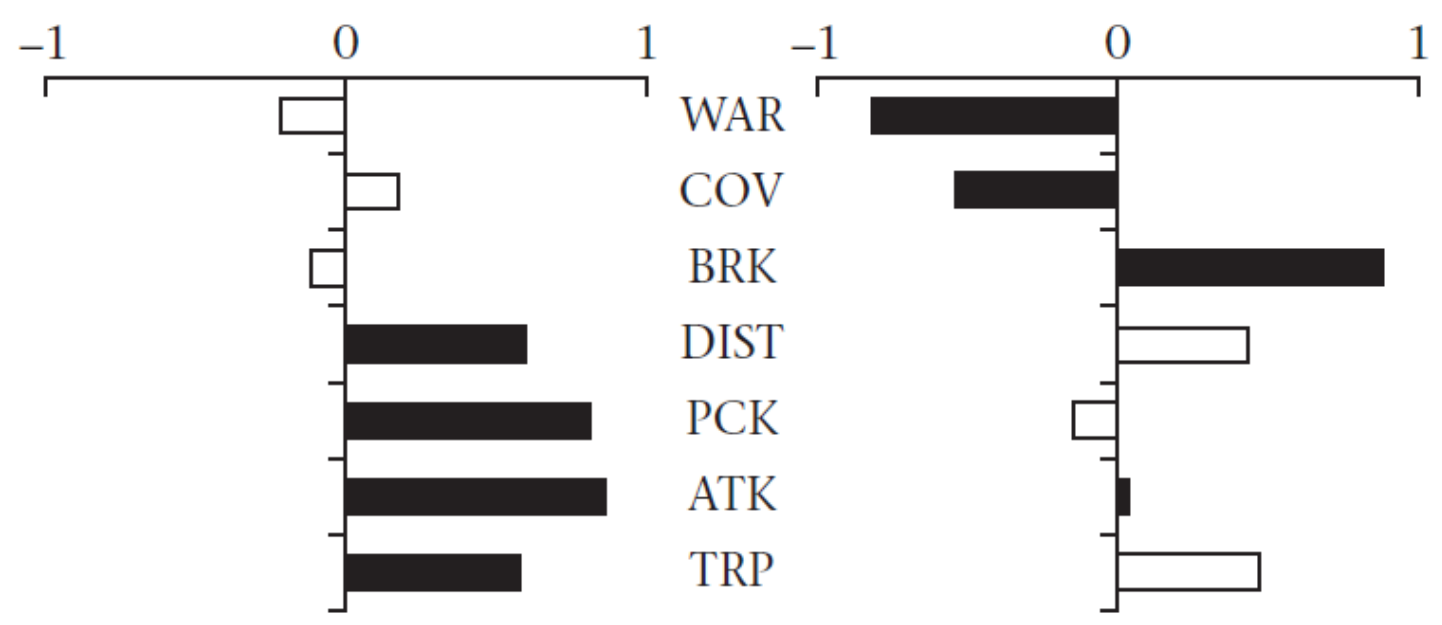

Figure 1. Maternal behaviour evaluated by the loadings of the seven maternal traits on the first two axes of a PCA ( $N=14 \times 3$ repetitions). Factor 1 accounted for $29.9 \%$ of the total variation and had large positive loadings for pecks (PCK), attacks (ATK), trampling (TRP) and distance to chicks (DIST) and was thus labelled 'aggression'. Factor 2 accounted for $28.0 \%$ of the total variation and was labelled 'rejection versus warming' as it indicated large negative loadings for time spent warming (WAR) and proportion of covering posture (COV) and large positive loadings for maternal initiation of warming breaks (BRK). 

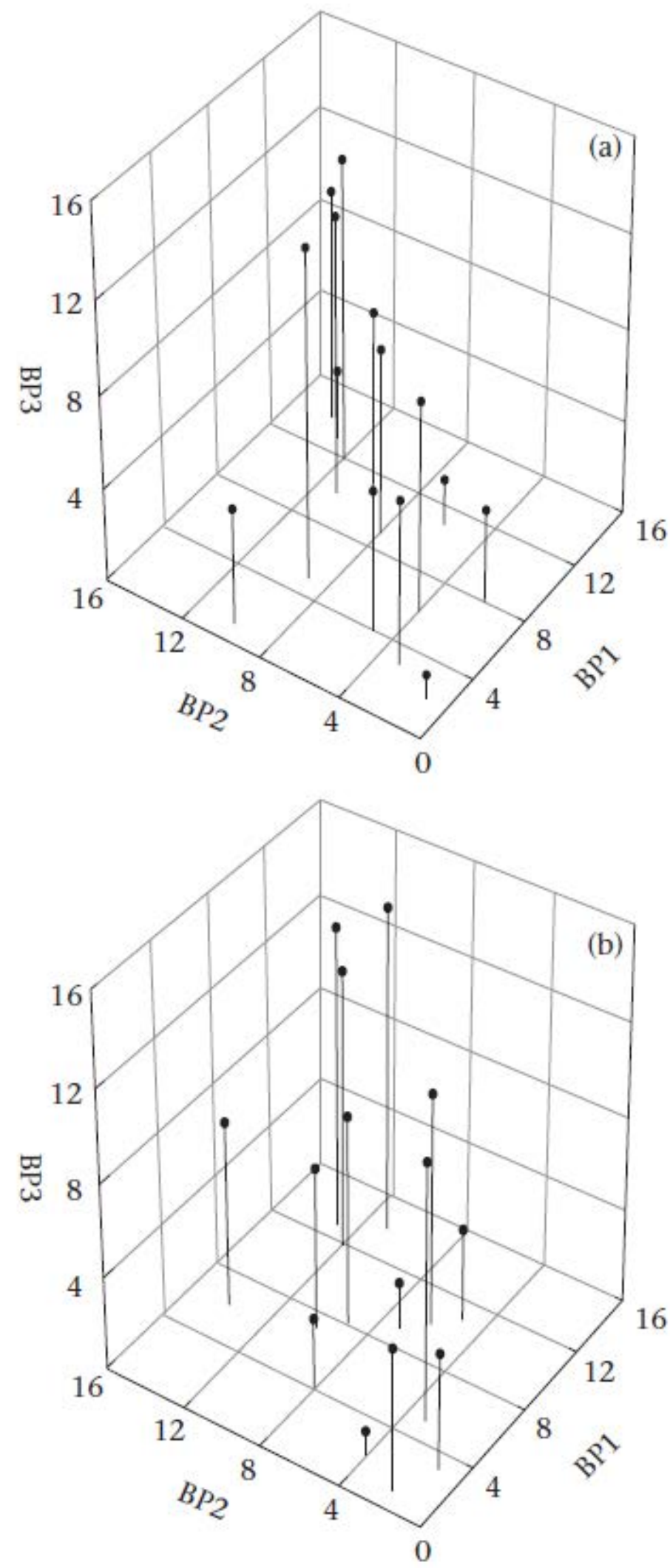

Figure 2. Consistency of individual differences. Females' (a) aggression and (b) rejection 291 scores (ranked) plotted on a three-dimensional graph for BP1, 2 and $3(N=14)$. 


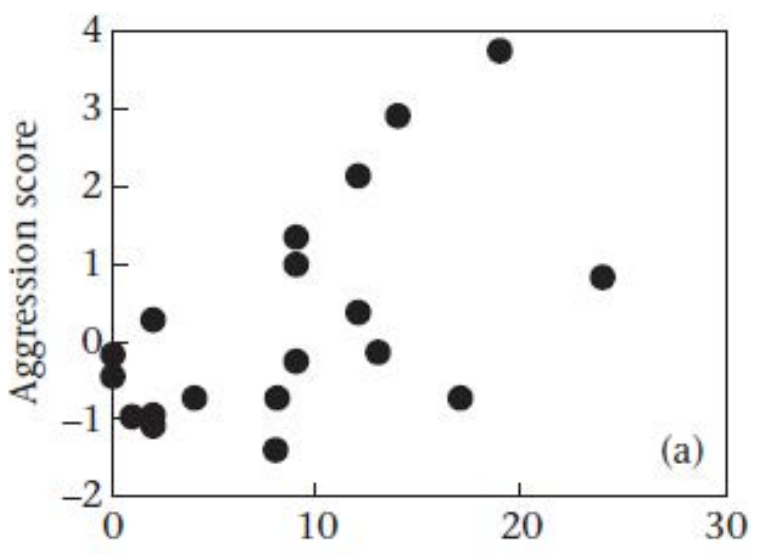

Avoidance of novel object

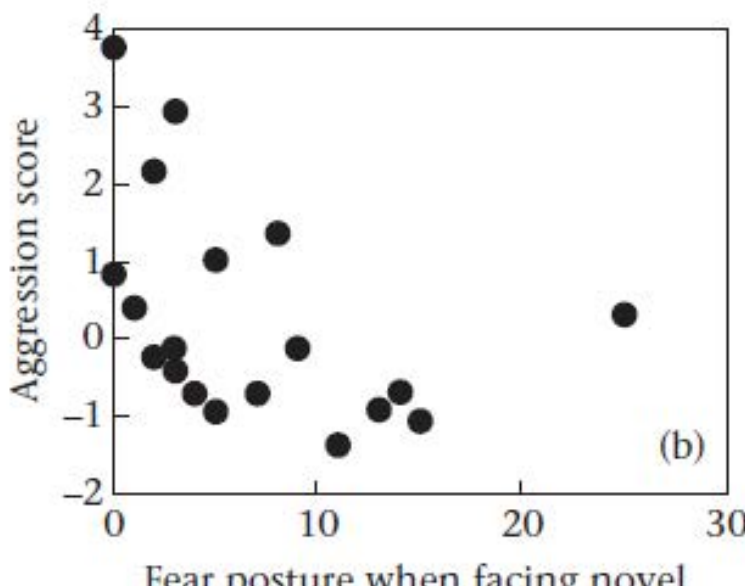

object

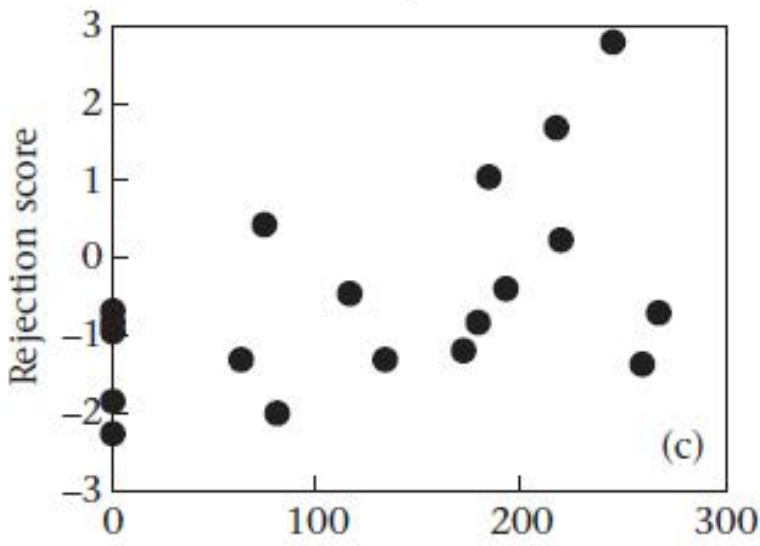

Time spent in contact with unfamiliar conspecifics

Figure 3. Females' personality and maternal styles. Females' aggression scores when 294 maternal in relation to (a) active (frequency of avoidances) and (b) passive (frequency of fear 295 posture) reactions towards a novel object and (c) rejection scores in relation to sociality towards 296 unfamiliar conspecifics $(N=14)$. 


\section{DISCUSSION}

Our results provide evidence for the existence of maternal styles in Japanese quail and illustrate close links between mothers' temperaments and their maternal style. They also show marked consequences of maternal styles for the chicks' temperaments.

\section{Existence of mothering styles in Japanese quail}

First, our study revealed that naturally occurring individual differences in the characteristics of maternal care can be summarized by two principal independent dimensions: mothers' aggressiveness and their propensity to warm or reject their chicks. The consistency of these individual differences demonstrates the existence of individual signatures of maternal care that remain resistant to differences between broods and to the effects of maternal age and increased experience already reported for this species (Pittet et al., 2012, 2013). The present work is, to our knowledge, the first reported case of maternal styles in a nonmammalian species.

\section{Mothers' temperament and maternal style}

Our results indicate that the way females react to a novel object (other than their general fearfulness) is related to their aggressiveness towards chicks. Maternal behaviour could be driven by neophobia during the first few days of a breeding period: females that reacted actively to a novel object also reacted actively to chicks, attacking and pecking them and made flight attempts (leading to increased mother-chick distances and trampling). Conversely, females that reacted to novelty more passively also showed restrained reactions to chicks' solicitations. Fearfulness and particularly neophobia have also been reported to affect the quality of mammals' first interactions with their offspring and subsequently to affect their survival 

Neindre, 1998).

We also found that females that stayed at some distance from the social stimulus in the runway test rejected their offspring less. This is analogous to behaviour reported in the mammalian literature. Primates' maternal styles have been reported to depend on social context (see Fairbanks, 1996 for review), but also on mothers' sociality level (Murray, Cooper, Creswell, Schofield, \& Sack, 2007). Indeed, primate females showing social anxiety and avoiding social contact delay their infants' emancipation by being overprotective, which can be considered the converse of maternal rejection (Schino et al., 2001). In our study, this link between rejection and emancipation, at least on the mothers' side, is confirmed by our separation test results: less social and less rejecting females remained reactive to separation from their chicks when they were removed at an age when they naturally disperse. Obviously, this link between maternal sociality and rejection is most relevant in rich social environments when offspring risk aggression from conspecifics. Further investigations, testing maternal care of precocial birds in richer social environments, should yield interesting results concerning this relationship. From a neurohormonal point of view, oxytocin is involved in the expression of mammals' social and maternal behaviour (Donaldson \& Young, 2008; Nowak, Keller, \& Lévy, 2011); in birds this link could be provided by the nonapeptide mesotocin which is implicated in both social flocking behaviour and maternal behaviour (Chokchaloemwong et al., 2013; Goodson, Kelly, \& Kingsbury, 2012; Goodson, Schrock, Klatt, Kabelik, \& Kingsbury, 2009).

339 The relationships between temperament traits related to neophobia or sociality and maternal 340 styles evidenced here in birds show interesting similarities with reports on mammals. Given the common points in the set-up of maternal styles and personalities (consistency of individual differences mainly defined by genetic and early experience) and the implication of neuroendocrine systems, we hypothesize that the association between maternal styles and 
personalities could be a universal vertebrate trait, as the maternal care period is a challenging situation particularly fitted for the expression of individual differences.

\section{Maternal styles and chicks' temperament}

Agreeing with reports on mammal species, our study demonstrates that maternal behaviour can influence offspring personality. We showed that chicks' social motivation levels were correlated with their foster mother's rejection scores. Filial imprinting could be involved here. Indeed, hens' behaviour can influence the establishment of a filial bond (ten Cate, 1989) and previous observations indicated that poorly warmed chicks quickly shift their thermoregulation strategies to warming one another (Pittet et al., 2012). If the establishment of imprinting implies mechanisms similar to those involved in associative learning (van Kampen, 1996), the morerejected chicks should logically develop a weaker bond with their mothers but a stronger bond with the rest of the brood more likely to meet their physiological needs. A similar relationship between rejection and development of sociality has been reported for several primate species. Indeed, maternal rejection (within a normal range) has been reported to reduce nonhuman primates' fearfulness expressed towards a social stimulus (Schino et al., 2001), and humans' overprotective behaviour can induce social anxiety disorders (Spokas \& Heimberg, 2009). Our present experiment does not allow us to draw any conclusions about whether maternal styles are involved in the transmission of emotional reactivity, probably because the chicks' reactions to stressful situations are mainly socially oriented at this age or because individual differences between mothers were not sufficient. We could also consider that females' reactions to stressful situations are acquired by chicks via observational learning. This mechanism would imply that fear reactions are not transmitted via maternal care but via fear reactions expressed by females during the breeding period. Further investigations using divergently selected females (Mills \& Faure, 1991) should highlight more precisely the influences of maternal fearfulness on chicks' behaviour. 
Finally, precocial birds' maternal effects are known to be strong as some of the behavioural traits of mothers are transmitted to their foster chicks (Formanek et al., 2008; Richard-Yris et al., 2005). Our study demonstrates, for the first time, that maternal styles are implied in these influences in birds. Our results show that care characteristics enable the transmission of social motivation from mothers to foster chicks through a pattern of successive influences: a female's social motivation influences her rejection score during the maternal stage, a maternal dimension that, in turn, affects chicks' social motivation.

\section{Conclusion}

Mammals' maternal styles have been a key focus for the investigation of maternal behaviour, its influence on offspring behaviour and associated mechanisms in a large range of fields. Our present findings demonstrate for the first time the existence of maternal styles in birds and their relationships with females' temperaments. Our results also highlight influences of maternal styles on chicks' development and demonstrate that maternal care is involved in the nongenetic transmission of behavioural characteristics. Given the current need to develop new models to investigate the impact of early experience on neurological and behavioural development (Lupien, McEwen, Gunnar, \& Heim, 2009), we anticipate this study to be a starting point for the integration of precocial birds into investigations of these issues.

\section{ACKNOWLEDGMENTS}

We thank C. Petton for his help in rearing and maintaining the quail. We are grateful to Dr Ann Cloarec for improving the writing of the manuscript and to the referees for their interesting and helpful comments. 


\section{REFERENCES}

Albers, P., Timmermans, P., \& Vossen, J. (1999). Evidence for the existence of mothering styles in guinea pigs (Cavia aperea f. porcellus). Behaviour, 136, 469-479.

Altmann, J. (1980). Baboon mothers and infants. Cambridge, MA: Harvard University Press.

Bertin, A., \& Richard-Yris, M. A. (2005). Mothering during early development influences subsequent emotional and social behaviour in Japanese quail. Journal of Experimental Zoology Part A: Comparative Experimental Biology, 303, 792-801.

Catalani, A., Casolini, P., Scaccianoce, S., Patacchioli, F. ., Spinozzi, P., \& Angelucci, L. (2000). Maternal corticosterone during lactation permanently affects brain corticosteroid receptors, stress response and behaviour in rat progeny. Neuroscience, 100, 319-325.

Champagne, F. A., Francis, D. D., Mar, A., \& Meaney, M. J. (2003). Variations in maternal care in the rat as a mediating influence for the effects of environment on development. Physiology \& Behavior, 79, 359-371.

Chokchaloemwong, D., Prakobsaeng, N., Sartsoongnoen, N., Kosonsiriluk, S., El Halawani, M., \& Chaiseha, Y. (2013). Mesotocin and maternal care of chicks in native Thai hens (Gallus domesticus). Hormones and Behavior, 64, 53-69.

Dingemanse, N. J., Both, C., Drent, P. J., \& Tinbergen, J. M. (2004). Fitness consequences of avian personalities in a fluctuating environment. Proceedings of the Royal Society B, 271, $847-852$.

Donaldson, Z. R., \& Young, L. J. (2008). Oxytocin, vasopressin, and the neurogenetics of sociality. Science, 322, 900-904.

Dwyer, C. (2008). The welfare of the neonatal lamb. Small Ruminant Research, 76, 31-41. 
Dwyer, C. M., \& Lawrence, A. B. (2000). Maternal behaviour in domestic sheep (Ovis aries):

414 Constancy and change with maternal experience. Behaviour, 137, 1391-1413.

415 Fairbanks, L. A. (1996). Individual differences in maternal style: Causes and consequences 416 for mothers and offspring. Parental Care: Evolution, Mechanisms, and Adaptive Significance, $25,579-611$.

Formanek, L., Houdelier, C., Lumineau, S., Bertin, A., \& Richard-Yris, M. A. (2008).

Maternal epigenetic transmission of social motivation in birds. Ethology, 114, 817-826.

Goodson, J. L., Schrock, S. E., Klatt, J. D., Kabelik, D., \& Kingsbury, M. A. (2009).

Mesotocin and nonapeptide receptors promote estrildid flocking behavior. Science, 325, 862866.

Goodson, J. L., Kelly, A. M., \& Kingsbury, M. A. (2012). Evolving nonapeptide mechanisms 424 of gregariousness and social diversity in birds. Hormones and Behavior, 61, 239-250.

Groothuis, T., \& Maestripieri, D. (2013). Parental influences on offspring personality traits in oviparous and placental vertebrates. In C. Carere \& D. Maestripieri (Eds.), Animal

427 personalities: Behavior, physiology, and evolution (pp. 317-352). Chicago : The University 428 of Chicago Press.

429 Guyomarc'h, J. C., \& Saint-Jalme, M. (1986). La reproduction chez la caille des blés 430 (Coturnix c. coturnix). II: Croissance et développement sexuel des jeunes. Gibier Faune 431 Sauvage, 3, 281-295. 
Hinde, K., \& Capitanio, J. P. (2010). Lactational programming? Mother's milk energy predicts infant behavior and temperament in rhesus macaques (Macaca mulatta). American Journal of Primatology, 72, 522-529.

Hollander, F. A., Van Overveld, T., Tokka, I., \& Matthysen, E. (2008). Personality and nest defence in the great tit (Parus major). Ethology, 114, 405-412.

Houdelier, C., Lumineau, S., Bertin, A., Guibert, F., De Margerie, E., Augery, M., \& RichardYris, M. A. (2011). Development of fearfulness in birds: Genetic factors modulate nongenetic maternal influences. PloS One, 6, e14604.

Jones, R. B., Satterlee, D. G., \& Cadd, G. G. (1999). Timidity in Japanese quail: Effects of vitamin $\mathrm{C}$ and divergent selection for adrenocortical response. Physiology \& Behavior, 67, $117-120$.

Kikusui, T., Isaka, Y., \& Mori, Y. (2005). Early weaning deprives mouse pups of maternal care and decreases their maternal behavior in adulthood. Behavioural Brain Research, 162, $200-206$.

Lupien, S. J., McEwen, B. S., Gunnar, M. R., \& Heim, C. (2009). Effects of stress throughout the lifespan on the brain, behaviour and cognition. Nature Reviews Neuroscience, 10, 434445.

Maestripieri, D. (1993). Maternal anxiety in rhesus macaques (macaca mulatta): II. Emotional bases of individual differences in mothering style. Ethology, 95, 32-42.

Mills, A. D., \& Faure, J. M. (1991). Divergent selection for duration of tonic immobility and social reinstatement behavior in Japanese quail (Coturnix coturnix japonica) chicks. Journal of Comparative Psychology, 105, 25-38. 
Murphy, P. M., Lindsay, D. R., \& Le Neindre, P. (1998). Temperament of Merino ewes influences maternal behaviour and survival of lambs. In Veissier, I., \& Boissy, A. (Eds.), Proceedings of the 32nd international congress of the International Society for Applied Ethology (page. 131). Clermont-Ferrand : I.N.R.A. Edition.

Murray, L., Cooper, P., Creswell, C., Schofield, E., \& Sack, C. (2007). The effects of maternal social phobia on mother-infant interactions and infant social responsiveness. Journal of Child Psychology and Psychiatry, 48, 45-52.

Mutzel, A., Dingemanse, N. J., Araya-Ajoy, Y. G., \& Kempenaers, B. (2013). Parental provisioning behaviour plays a key role in linking personality with reproductive success. Proceedings of the Royal Society B, 280, 2013019.

Nelson, R.J. (1995). Parental behavior. In R.J. Nelson (Ed.), An introduction to behavioral endocrinology (pp. 289-336). Sunderland, MA: Sinauer.

Nowak, R., Keller, M., \& Lévy, F. (2011). Mother-young relationships in sheep: A model for a multidisciplinary approach of the study of attachment in mammals. Journal of Neuroendocrinology, 23, 1042-1053.

Pittet, F., Coignard, M., Houdelier, C., Richard-Yris, M. A., \& Lumineau, S. (2012). Age affects the expression of maternal care and subsequent behavioural development of offspring in a precocial bird. PLOS ONE, 7, e36835.

Pittet, F., Coignard, M., Houdelier, C., Richard-Yris, M.-A., \& Lumineau, S. (2013). Effects of maternal experience on fearfulness and maternal behaviour in a precocial bird. Animal Behaviour, 85, 797-805. 
477 Plush, K. J., Hebart, M. L., Brien, F. D., \& Hynd, P. I. (2011). The genetics of temperament in 478 Merino sheep and relationships with lamb survival. Applied Animal Behaviour Science, 134, $479 \quad 130-135$.

480

481

482

483

Réale, D., Reader, S. M., Sol, D., McDougall, P. T., \& Dingemanse, N. J. (2007). Integrating animal temperament within ecology and evolution. Biological Reviews, 82, 291-318.

Richard-Yris, M. A., Michel, N., \& Bertin, A. (2005). Nongenomic inheritance of emotional reactivity in Japanese quail. Developmental Psychobiology, 46, 1-12.

Rodríguez-Prieto, I., Martín, J., \& Fernández-Juricic, E. (2011). Individual variation in behavioural plasticity: direct and indirect effects of boldness, exploration and sociability on habituation to predators in lizards. Proceedings of the Royal Society B, 278, 266-273.

Roulin, A., Dreiss, A. N., \& Kölliker, M. (2010). Evolutionary perspective on the interplay between family life, and parent and offspring personality. Ethology, 116, 787-796.

Schino, G., Speranza, L., \& Troisi, A. (2001). Early maternal rejection and later social anxiety in juvenile and adult Japanese macaques. Developmental Psychobiology, 38, 186-190.

Schwagmeyer, P. L., \& Mock, D. W. (2003). How consistently are good parents good parents? Repeatability of parental care in the house sparrow, Passer domesticus. Ethology, 109, 303-313.

Smith, B. R., \& Blumstein, D. T. (2008). Fitness consequences of personality: A metaanalysis. Behavioral Ecology, 19, 448-455.

Spinka, M., Illmann, G., de Jonge, F., Andersson, M., Schuurman, T., \& Jensen, P. (2000). Dimensions of maternal behaviour characteristics in domestic and wild $\times$ domestic crossbred sows. Applied Animal Behaviour Science, 70, 99-114. 
499

500

501

502

503

504

505

506

507

508

509

510

511

512

513

514

515

516

517

518

Spokas, M., \& Heimberg, R. (2009). Overprotective parenting, social anxiety, and external locus of control: Cross-sectional and longitudinal relationships. Cognitive Therapy and Research, 33, 543-551.

Stamps, J. A., \& Groothuis, T. G. G. (2010). Developmental perspectives on personality: implications for ecological and evolutionary studies of individual differences. Philosophical Transactions of the Royal Society B, 365, 4029-4041.

Taka-Tsukasa, N. (1935). The birds of Nippon (Vol. 1). London: Witherby.

ten Cate, C. (1989). Stimulus movement, hen behavior and filial imprinting in Japanese quail (Coturnix coturnix japonica). Ethology, 82, 287-306.

Van Ijzendoorn, M. H., Moran, G., Belsky, J., Pederson, D., Bakermans-Kranenburg, M. J., \& Kneppers, K. (2000). The similarity of siblings' attachments to their mother. Child Development, 71, 1086-1098.

Van Kampen, H. (1996). A framework for the study of filial imprinting and the development of attachment. Psychonomic Bulletin \& Review, 3, 3-20.

Weaver, I. C. G., Cervoni, N., Champagne, F. A., D’Alessio, A. C., Sharma, S., Seckl, J. R., Dymov, S., Szyf, M., \& Meaney, M. J. (2004). Epigenetic programming by maternal behavior. Nature Neuroscience, 7, 847-854. 
Details of behavioural tests

Each test subject was removed from its home cage and transported in the dark, in a

524

525 wooden box $(18 \times 18 \times 18 \mathrm{~cm})$. This box was then placed on the left side of the apparatus: a large and well-lit wooden box (62x60 $\mathrm{cm}$ and $33 \mathrm{~cm}$ high) with wood shavings covering the floor and an observation window. When the transport box was placed in the apparatus, it was kept closed for $1 \mathrm{~min}$. Then, the door was left open for $3 \mathrm{~min}$. Latencies for the subject to pass its head out of the box and to emerge completely were recorded.

\section{Novel-object test}

This test assessed neophobia by the reactions of subjects to the presence of an unfamiliar object. Mothers were tested in their home cage, but chicks had to be socially isolated and were consequently tested in a polyhedral open field $\left(1 \mathrm{~m}^{2}, 60 \mathrm{~cm}\right.$ high) after a $10 \mathrm{~min}$ habituation. The novel stimulus was an unfamiliar plastic T-shaped object. During a 10 min focal sample the experimenter recorded latency to approach the object, frequency of locomotion (walks, runs) and frequency of fear behaviours including escape, withdrawal (slowly approach the object and then walk away while keeping it in sight), jumps and fear postures (freezing in crouching posture).

\section{Open-field test}

Chicks were placed individually in the dark in the centre of a polyhedral arena $\left(1 \mathrm{~m}^{2}, 60 \mathrm{~cm}\right.$ high) with white plastic walls and a linoleum floor. The experiment started when the light was switched on, and, hidden behind a one-way mirror, the experimenter recorded latency of the 
542 first distress call, the number of distress calls, the latency of the first step, the number of steps

543 and the frequency of observation, exploration and maintenance activities for $5 \mathrm{~min}$.

The apparatus was a $100 \mathrm{~cm}$ long plastic tunnel with walls $20 \mathrm{~cm}$ high. Test subjects were transported individually in a wooden box $(18 \times 18 \times 18 \mathrm{~cm})$, which was then placed at the tunnel

547 entrance. At the other end of the tunnel was a cage $(20 \times 35 \mathrm{~cm}$ and $20 \mathrm{~cm}$ high) containing three

548 unfamiliar conspecifics of the same age as the tested individual, representing a social stimulus.

549 The corridor was divided into four zones: the closest zone to the social stimulus, 'one bird long'

550 (zone P) and three equal $32 \mathrm{~cm}$ long zones called, from the entrance to zone P: zones A

551 (beginning of the tunnel), B (middle) and C (end of the tunnel). One minute after the transport

552 box had been put in place, the door was opened and the subject was observed for 5 min. The

553 experimenter noted the time spent in each zone. 
556 Table A1. Friedman tests measuring effects of age of chicks and experience of mother on maternal traits

\begin{tabular}{|c|c|c|c|c|c|c|}
\hline & \multicolumn{3}{|c|}{ Effects of age of chicks } & \multicolumn{3}{|c|}{ Effects of maternal experience } \\
\hline & $F$ & $P$ & PHD pair comparison & $F$ & $P$ & BP pair comparison \\
\hline Warming chicks & 47.87 & $<0.0001$ & PHD2,3 > PHD 7 - PHD2,3,4,5>PHD9 & 18.69 & $<0.0001$ & $\mathrm{BP} 1,2<\mathrm{BP} 0$ \\
\hline Attacks & 5.96 & 0.31 & - & 1.10 & 0.78 & - \\
\hline Breaks from warming & 7.73 & 0.17 & - & 5.40 & 0.14 & - \\
\hline Pecks & 8.83 & 0.12 & - & 8.39 & 0.04 & - \\
\hline Distance from chicks & 25.63 & $<0.0001$ & PHD2,3 < PHD7 - PHD2,3 < PHD 9 & 28.20 & $<0.0001$ & $\mathrm{BP} 1,2,3>\mathrm{BP} 0$ \\
\hline Covering posture & 32.08 & $<0.0001$ & PHD2,3,4,5 > PHD 9 & 6.91 & 0.075 & - \\
\hline Trampling & 0.96 & 0.96 & - & 3.39 & 0.34 & - \\
\hline
\end{tabular}

558 Age of chicks (PHD): $N=14, d f=5, F_{\text {crit }}=11.07$. Pair comparison: Nemenyi method

559 with Bonferroni alpha correction: $P=0.003$. Maternal experience $(\mathrm{BP}): N=14, d f=3, F_{\text {crit }}=$

560 7.82. Pair comparison: Nemenyi method with Bonferroni alpha correction: $P=0.008$. 